\title{
Daily Dose
}

National Cancer Institute

\section{Source}

National Cancer Institute. Daily Dose. NCI Thesaurus. Code C70888.

A specified quantity of a therapeutic agent to which an individual can be exposed to or was exposed to, during a one-day period. In the clinical study protocol, the label and other documentation the type of daily dose must be specified. 